\title{
Logistic service branch as an economic mesosystem
}

\author{
Anna Wiktorowska-Jasik, PhD \\ West Pomeranian University of Technology in Szczecin \\ Poland \\ annawik@zut.edu.pl
}

\begin{abstract}
The article presents matters related to the branch as an object of economic research. The logistic service branch is a detailed object of analysis, examined as an economic mesosystem. The purpose of the article is to present dependences taking place between elements of this mesosystem, namely the domestic economy, and companies from the logistic branch as well as how these dependences affect the quality and the competitiveness of provided services. In addition, the article brings closer self-regulation models of the logistic services market with particular focus on the impact of the evolutionary economics trend. Participants of the logistic service market are also presented, emphasizing the market's modular structure and this structure's configuration in Poland. Considerations on the impact of contemporary general economic trends on mechanisms regulating the branch also take a significant place as does the behavior of particular elements of this mesosystem.
\end{abstract}

Keywords: branch, logistic service, mesosystem, logistic service market, logistic operator, innovations, competitiveness, economy sector

JEL classification: L 11, L 87

\section{INTRODUCTION}

The logistic service branch is one of the key segments of highly-developed economies. This is proven both by its revenues as well as the percentage share in the gross domestic product. This branch is a system of entities, organizations and institutions, separated from the economic environment, the activities of which are directly or indirectly related to logistic services. It is an ordered whole including transport-shipping-logistic companies and related institutions, with a diverse scope, service profile and size. The basic scope of activities of the logistic service branch refers to physical movement of people and cargo but with particular focus on the optimization of this process towards ensuring high effectiveness and a relevant service level. The article formulates the following thesis: Logistics services industry has a strong impact on other industries and it is an important factor for their development. Therefore, the logistic service branch is analyzed as an economic mesosystem. The adopted assumption was verified by the analysis factors which improve the flow of products in supply chains. 


\section{ESSENCE OF THE BRANCH AND BRANCH MARKETS}

The notion branch is considered quite an obvious one and is mostly identified with a specified space in which business entities of a similar management profile operate. This space and the scope of impact is, to a certain extent, an arbitrary value since it does not have any clearly designated boundaries of these activities. On the other hand, the levels of its research as an economic subsystem are typical of the branch. The branch as an object of economic research is the case of a meso-economic level. On the other hand, mesoeconomics is the economics of sectors, sections and branches of the domestic economy, global branches, regions and social groups. The main areas of research for mesoeconomists are matters related to the dynamics of mesosystems, changes in their structure as well as the behavior of the mesosystem's members (Gorynia 2000: 36). There are also opinions that mesoeconomics should focus on analyzing the economic reality abandoning the large degree of generalization and abstraction. As a result, it would achieve a heavily practical dimension. The literature on the subject often uses the definition that mesoeconomics is a peculiar branch economics, namely an independent research area. The main directions of research are any economic systems located at the intermediate level, namely between the domestic economy and the level of single companies and institutions. One of the more significant directions of interests among them is analysis referring to branches (Janasz, 1997:14-15).

The branch in which the company operates is essentially determined by the manner of production organization which, in turn, results from previous decisions determining the technology and then the distribution channels. Another matter which is often of major importance is the selection of the market to which the supply is directed. This selection depends on the specific nature of the manufactured product as well as the geographic location, and the membership in the sector is its derivative. The presented considerations entitle to present two separate opinions relating to the branch. One of them states that the branch is a group of specified manufacturers/service providers manufacturing the same or substitute products/services. The second approach present the branch as a market satisfying a given need presented by current and potential recipients. These two approaches result in the lack of integrity in approaches to these matters and the difficulty in using tools and techniques helpful to understand the sector, branch and market. In this case the notion branch will be used to define groups of companies of a similar operation profile and the market will be separated as a separate notion.

There is feedback between each industrial branch and the market. On the one hand, the branch is an element of the market which results from the fact that it participates in processes taking place on the market. On the other hand, however, it is assumed that the share of a given branch in the market is as big as the branch's impact on the market and market processes taking place in it. It is also worth emphasizing that the market economy has a unique model in particular countries despite the fact that it is based on universal principles. A characteristic feature is that each country forms specific solutions, including economic institutions, which specify this market. In addition, each market is not resistant to evolution, fluctuations and undergoes the impacts of various entities, including governments, specified groups of citizens, companies and social and political organizations (Janasz, 2000: 26). This results from the fact that clear differences appear between these two notions (branch, market). One of them is definitely the range of impact and the other one recipients of the product/service offer. In the case of the market its boundaries are defined by consumers' possibilities to replace one product with another one and recipients include everyone who find the offer suitable in terms of availability, the level of satisfying expectations and the price. This means that a given market is defined by the conditions of demand, is based on consumers' needs and is characterized by the law of "one price". On the other hand, the branch is determined by the conditions of supply, is strictly based on a specified production technology and is defined by markets intentionally selected by companies. 
To sum up - any analyses on the mesoeconomic level relate to these entities which are the link between the macroeconomic and the microeconomic level. They definitely include branches. Thus, the economics of the branch is both a fragment of mesoeconomics as well as a relatively independent research area. The intensive development of interest in how branches function mainly results from the fact that the so-called branch environment is the basic determinant of companies' behavior where the object of research is the economics of sectors. Matters analyzed in the mesoeconomic area include, among others, matters of the dynamics in mesosystems, changes in their structure, the analysis of the mesosystem members behavior, etc. The practical nature of mesoeconomics is also emphasized. It should focus on examining the economic reality abandoning the large degree of generalization.

\section{MODELS FOR REGULATING BRANCH MARKETS}

Due to the established and commonly adopted division of the economy into sectors, it will undoubtedly depend on transformations taking place in the sectors. Therefore, changes in the economy are the effects of changes which take place in its particular branches. For this reason models similar to those used in explaining the phenomena taking place in the sectors are used to analyze the economy. These include, among others: models concerning regulation the so-called self-regulation of the branch. They assume that the regulation of the behavior of the branch's participants involves the diversity of companies' reactions to the environment. This, in turn, makes it possible to divide the models into two groups:

1. Models assuming a high level of determinism of the behavior of business entities but with the assumption of the leading role for the market mechanism in the natural selection of entities belonging to the branch. They include: the perfect market model, the questioned markets theory as well as Clark's concept.

2. Models putting emphasis on the role of strategic behavior, activism and the autonomy of behavior from companies belonging to the branch. They include: Mason's concepts, Bain's paradigm (Bain, 1959), Porter's branch model (Porter 1992: 21).

The presented groups of models are characterized by a clear representative character of specified theoretical trends relating to the branch matters. They include, among others, the theory of branch organization, typical of models from the first group as well as the trend of strategic behavior for models from the second group. It is necessary, however, to point out that in this case we may also find mixed features, namely models from the second group may be included both in the branch organization trend and the strategic trend. With regard to research on profitability and the branch's growth potential according to the strategic trend it is possible to examine the organization and the branch's behavior taking into account Bain's paradigm, Porter's branch model, the normative trend as well as the global branches concept which was formed as a result of disappearing the significance of administrative borders between countries.

When analyzing the theories explaining the phenomena taking place in the sectors and, in particular, taking into account the evolution and development of branches, the following are of significance the theory of evolution.

The entire branch theory emphasizes the impact of the evolutionary economics trend which, to a large extent, brings the branch analysis to define dynamic processes taking place in companies. The intensity of these processes depends on the openness to innovations. The following are analyzed in a special manner: relations taking place between the structure of markets, the size of companies as well as the intensity of innovative processes. The dependence between the branch's life cycle and moving from innovations to product modification in subsequent phases of the life cycle as well as the dependence of entering and exiting the branch for particular phases of the branch's life cycle are also taken into account. These analyses demonstrate 
a wide application of the evolutionary economics trend in the study of dependences between the structure of a given branch and the intensity of its evolutionary activities. It should be emphasized that the following are considered the most important in the field of evolutionary economics: the occurrence of continuous and irreversible processes related to changes in the structure as well as a systematic increase in knowledge. This opinion mostly results from the fact that innovations are the basis for each progress, including progress in the branch.

To sum up the considerations related to the evolutionary approach to the analysis of dynamic processes taking place in the branch we should say that they are diverse in terms of their pace and direction but they may be predicted. The accuracy of this forecast is the result of the knowledge of a number of factors, such as: long-term changes in the growth pace, serviced segments of buyers, learning speed of buyers, accumulation of experience, innovations in goods, marketing, processes, etc.

\section{MODULAR STRUCTURE OF LOGISTIC SERVICES MARKET}

The logistic service market is a specific structure in which continuous adaptation processes take place aimed at integrating the service offer with customer expectations as best as possible. These changes are mostly related to the type and scope of provided services. The trend of transforming service providers from narrow-profile into wide-profile logistic operators is visible as a result of these phenomena. Due to the fact that this group of services is provided, to a certain extent, for all sections of the economy, the specialization of the logistic services market needs to correspond to the expectations of all recipients. Therefore, the service offer from entities operating on the market needs to keep up with and practically be created along with modern technical-organizational solutions which take place in the activities of contemporary companies. The modular structure of the logistic services market is developing and changing under the influence of numerous factors. One of the most significant factors is globalization which contributed to the growth in the number of foreign delivery sources. Thus, operations with global production chains and the organization of distribution to a large number of customers on various global markets have become necessary. In addition, globalization unified both the standards of customer service as well as the flows of materials and information. All this results in the fact that the logistic service market is developing, to a considerable extent, as a result of the growing demand not only for services related to basic activities from logistic providers but also exceeding their scope, namely managing deliveries, stock which turn into managing entire supply chains. The characteristic feature of this market is the fact that it is very diverse. The diversity does not only apply to size and the service offer from entities operating on it but also to the scope of their activities and the strategic-operational assumptions themselves. The market includes entities which belong to the SME sector the task system of which includes the implementation of services at the executive level (transport, transshipment, warehousing, packaging, etc.) and their impact on the market is usually of a local range. The strategy of their activities is based on specialization regarding basic services directed to entities without a relevant potential for an unassisted execution of such services. Other participants of this market include entities offering a much wider range of services focused on logistic management of a number of processes taking place in production-commercial companies. The offer a complex service for entire supply chains on a domestic and international scale. The scope of impact of these entities as well as the rich service offer, including services generating added value, allowed them to obtain a significant competitive advantage. The strategy of their activities refers to cooperation with companies at the level of optimizing the supply chains, through offering them modern solutions of a technical-organizational nature, supported by IT systems (Ciesielski, 2005: 9). This approach created a new need on the market, namely seeking such offers which make it possible to 
purchase complex solutions from one service provider. Such solutions are considered to be the combination of several partial services in one offer which function as an integrated offer and may fully satisfy the customer in terms of his logistic needs. This means that the model of partial, fragmentary solving logistic problems has been replaced with complex service for an individual entity. It provides a given entity with full implementation of tasks related to physical movement and service of cargo at all levels of production-commercial processes as well as market research, creating marketing-distribution strategies, etc. The idea behind the complex logistic service is to ensure the purchase of an appropriate set of logistic solutions in one place, from one service provider (Krawczyk, 2011: 211). In practice the notion logistic services package is encountered which emphasizes the fact that logistic services are of a modular nature. This demonstrates that service suppliers sell particular modules combining them into such packages which meet customer expectations as best as possible (Mindur, 2008: 53). This means that each package consists of at least two elements for various areas of the company's activities and for various goods. It sometimes happens that such a package meets the requirement of complex logistic service for a given entity. However, there is a certain difficulty in presenting all permanent elements comprising a complex service. This mostly results from the high level of customization of the clients' needs and frequent market changes (Gołembska, 2001).

Diverse participants occupying various competitive positions are present on the logistic services market just like in any other segment of the economy. The diversity of entities functioning within the structures of the logistic services market mostly results from the selected service specialization but the company's size is also of significance. It is often the result of the number and the scope of provided services. The selected service specialization places a given company within the structure of the entire market. A very numerous group of companies with narrow service specialization scopes was formed in Poland as a result of deregulation on the transport market and as a result of liquidating numerous barriers. They mainly include road carriers with usually few means of transport (1-2 trucks) and the scope of their services is limited and hardly diverse. These are most often transport services, shipping-transport services, but they are rarely combined with warehousing. These companies are generally not competitors for logistic operators despite the fact that they often offer competitive prices. It is impossible to list them due to their great number. It is estimated that there are approx. 100,000 companies entered as transport companies in Poland and approx. $80 \%$ of them are small one-person family businesses. Such companies essentially have very little chances to become real logistic operators in the future. Some of them may survive on the market by merging with other companies or they may be taken over by larger logistic companies or possibly specialize in servicing specified market niches. Another group of participants on the logistic market includes widely-profiled service providers who specialize in providing a wide range of services, which include logistic operators. The level of an operator's efficiency of actions depends, above all, on owned capital and the IT system which enables, among others, warehouse management or tracking shipments (track and trace). This factor as well as the continuous growth in the demand for logistic services led to the creation of two various tendencies. The first is characterized by covering all activities in the logistic process by one entity (logistic operator). The second, on the other hand, indicates the specialization of services for the needs of a specific branch, e.g. the clothing or pharmaceutical branch. As a result, logistic companies may be divided into three groups (A. M. Jeszka 2013:63):

a) companies providing universal services based on uniform standards, e.g. courier shipments (DHL, DB Schenker, TNT, UPS, Kuehne+Nagel, etc.),

b) companies offering dedicated services used by important recipients, usually international corporations, the task of which is distribution in numerous countries (Raben, FM Logistics, etc.),

c) medium companies providing common services dedicated for recipients of each size. They are focused on providing services for both domestic and international entities. They specialize in a narrow technological scope for entities with specific, niche requirements. 
The abovementioned division of participants of the logistic service market forced the centralization of entities by means of mergers. As a result, global companies offering the most standardized and common services for a huge number of customers of a global range were created. This resulted in the fact that specialization became the domain of small and medium enterprises which extend their offer by services added and accompanying logistics. However, it should be emphasized that the most important factor determining the fact that logistic companies are a very favorable partner in business is the complex nature of service for the logistic operator. He is able to replace his customer in all activities related to physical movement of goods as well as managing this flow. However, it should be emphasized that the close cooperation of numerous entities with logistic companies is particularly good in the commercial branch of consumer goods. This requires a strict adjustment from logistic operators to customer requirements, mainly by: shortening the delivery time, the guaranteed delivery time, e.g. up to twelve hours, more flexible sizes of deliveries with a simultaneous increase of their quantity and a reduction in price.

The logistic service sector is characterized by the fact that a clear division into contractors of partial works related to the implementation of logistic tasks as well as into complex contractors is created among its participants. The latter declare themselves as companies offering such packages of services which may satisfy almost all customer expectations. All this may be summed up as: one branch, various concepts. This means that there are entities which see the success of their activities in expanding these activities, e.g. by expanding the share in the logistic market. Their strategy assumes that focusing on medium and large customers from a given branch and offering them cooperation with new areas will allow them to take over a significant part of this market. On the other hand, small companies with a smaller number of customers in their portfolio are able to take better care of them offering them almost the so-called custom-made services. In addition, there is always the risk of mismatch among a great number of customers (lack of compliance between the expectations and the offer).

It is estimated that around one hundred logistic operators are currently operating on the Polish market of logistic services. This considerable group of participants includes benchmark companies which have been leading the Polish market of logistic services for years. They include, among others, DHL, UPS, DPD, GSL, TNT, FM Logistic, DB Schenker, Raben, PEKAES, Spedimex, Siódemka and many others. Most of them are Polish companies belonging to global leaders of logistic services. On the other hand, smaller entities operating as road carriers are a definitely less numerous group which also affects the market (several dozen thousand family companies).

\section{CONTEMPORARY FACTORS REGULATING THE MARKET OF LOGISTIC SERVICES}

Companies from the logistic branch, just as all others, are subjected to continuous market tests. This test results in the competitive position a given company occupies in the sector it is operating in. A company's rank at a given market position is a process consisting of numerous stages and it is affected by various factors. However, the basic determinant is the competition. The branch's competitiveness is usually a process which is affected by both types of factors. This is a derivative of a synergic impact of an integrated bundle of mutually combined external and internal factors as well as activities undertaken by companies operating in the branch. These factors intermingle since they are present in the same time frame (Walczak, 2010). At this point it is important to emphasize the fact that the competitiveness of contemporary markets directly depends on the conditions and determinants of the competitiveness of the sector in which they function. Their position is affected also by the economic situation in a given country itself as well as the general global economic situation. This means that the market position is, to a large extent, dependent on factors present 
in the environment. On the other hand, achieving competitive advantage itself is a result of market competitiveness of products and services offered by the branch (Stankiewicz, 2006). Competitiveness on the logistic services market means complete readiness from entities on this market to implement both basic activities and these which generate added value. This means that the customer is expecting the entrusted logistic service to be implemented in such a manner so that it is enriched with an additional element such as, e.g. servicing returns, removing waste, etc. Therefore, an important factor for selecting the offer of a given service provider from the offers of various operators is the possibility to obtain a given added value. Basically, the difference between the offers from logistic providers is best visible at the level of additional services the diversity of which is significant. It is this element which allows service providers to compete with other entities, the buyers of services to reduce costs which are related to logistics. This situation affected the change in the behavior of all market participants but it affected logistic operators to the greatest extent. They constantly need to evolve in a direction which will allow them to catch up with the changing expectations of service buyers. These changes are assisted by technology (mainly information technology) which enabled changes regarding the organization, technique and technology of transportation. The development of the logistic services sector is, without a doubt, related to the development of these technologies, including supply chains and networks. To sum up, we may say that the condition for competitiveness and the main source of achieving competitive advantage on the logistic services market is combining various partial services into completeoffer packages. In this manner complex logistic solutions are developed which may meet the expectations for logistic service for both production and commercial companies. Contemporary factors regulating the logistic services market are mainly (Grudzewski, Hejduk, 2001: 52):

- the globalization of industries and structural changes in economies;

- the growing demand for logistic-transport services;

- changes in the organization of logistic systems and supply chains;

- the increase in the complexity of production-distribution processes;

- the acceleration of technological changes as well as shorter and shorter life cycles of goods/services;

- the positioning of transport-logistic companies as well as geographical-product diversification;

- the development of electronic commerce and its impact on the supply chain's configuration;

- the focus on logistic services according to the integrated supplier model;

- conditions resulting from the sustainable development of transport.

The globalization of the global economy, including the logistic services market, is best visible on the level of suppliers of these services. The number of entities dealing with this type of activities is enormous and their branch structure is heavily diverse. However, global logistic operators are leaders. Due to the fact that they are widely profiled service providers, they have a greater tender effectiveness. This also results from their high coordination of activities. Thus, they may affect the behavior of services buyers in a manner. In addition, globalization changes are reflected in the structures of economies resulting in changes also in the actions of recipients. Recipients select services from operators and they automatically affect the reduction in the number of smaller entities. This results in limiting the number of suppliers, which is often the result of company mergers, taking over their functions or markets operated by them. A significant difference is also the change in function assumptions of the global supply chain, namely putting special emphasis on:

- synchronizing actions in the supply chain - namely the ability to coordinate, organize and manage the flow (of goods, services, information and financial funds) in such a manner that functions of the supply chain are treated as a unit;

- raising the ability to adapt, defined as the agility of the supply chain, understood as the degree to which participants in the chain may change the their practices, processes, system structures and networks in reaction to unexpected events (Bujak, 2010), 
- optimization, as a result of which managing resources of the global supply chain, both tangible and intangible ones, own as well as outsourced - should lead to ensuring benefits to all participants of the supply chain;

- the speed with which flow within the supply chain takes place; it includes the speed of introducing new products to the market in a situation when the conditions change rapidly;

- profitability as a result of creating value by all activities as part of the supply chain.

The algorithm for assessing the agility of the supply chain according to various improving options is presented in Figure 1.

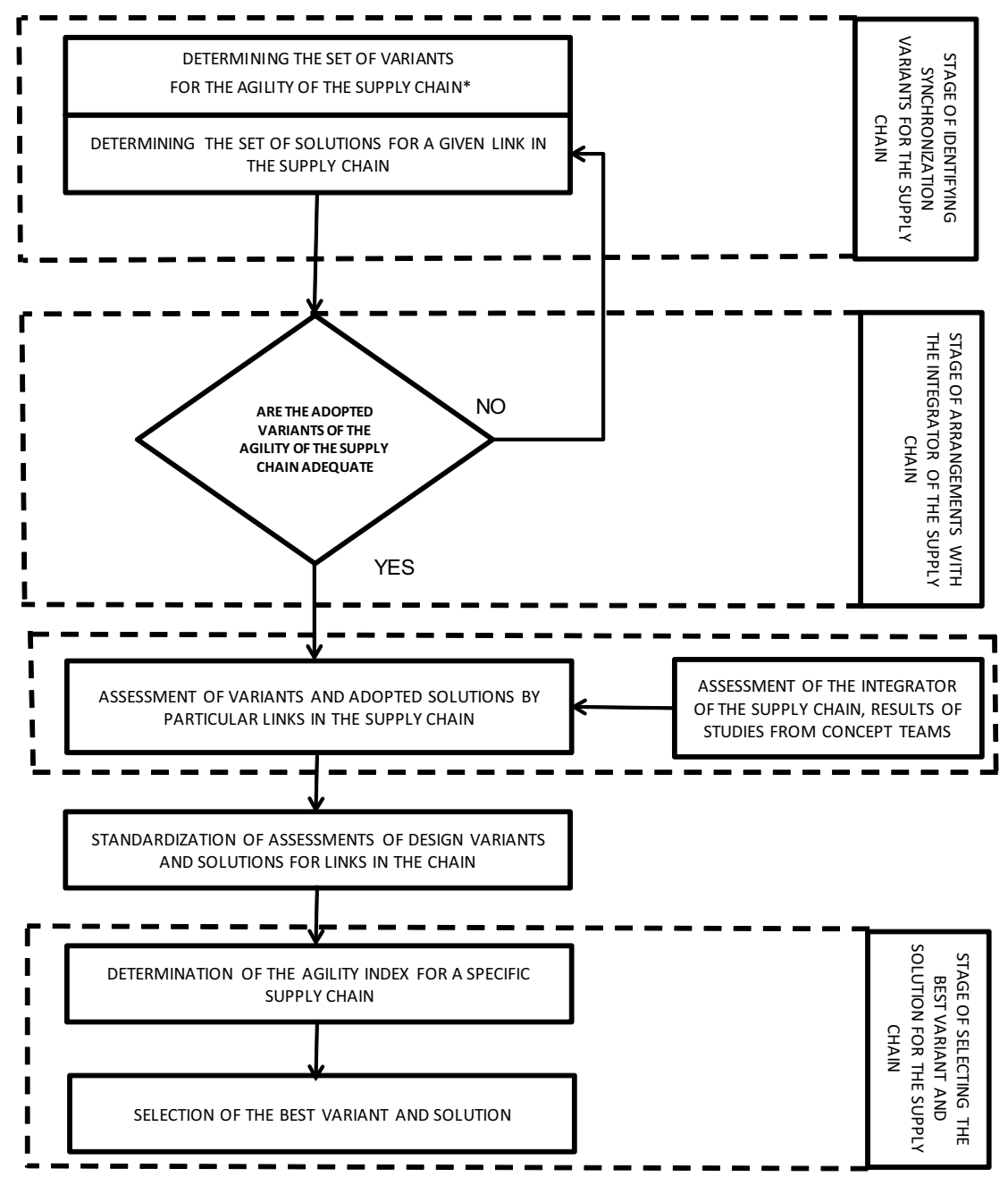

Variant 1 is based on the growth in agility through organizational improvements

Variant 2 is based on the growth in agility through infrastructural improvements

Figure 1 Algorithm for synchronizing activities in agile supply chain Source: prepared by the author 
To sum up we may assume the optimization of the supply chain means that emphasis should be put on an effective reduction in inventory, the growth in the number of quick entrances to new markets, the reduction and shortening of capital freezing time. In addition, the search should be focused on the possibilities to focus on basic activities in each area of the supply chain's functioning. The presented needs emphasize the strategic significance of a relevant level of speed, timeliness, reliability and safety of deliveries, namely a high agility level of the supply chain guaranteed by logistic services. In this respect, services from the group of express-courier services have become extremely attractive from the point of view of logistic challenges for production, commercial and service companies. This branch is currently considered the key infrastructural element of contemporary logistic, mainly distribution, systems. Operators providing courier-express services began specializing in branches offering services selected for the needs of each recipient. They are prepared to implement services related to increasingly complex customer needs, in particular with regard to providing complex services for the logistic branch as well as they adapt to the demand variability pace.

Additionally, a special role on the logistic services market is played by integrating companies which function on the basis of the integrated supplier model and expect a quicker increase in the sales of logistic services. Branches which are most often serviced according to this model include: the electronic, telecommunication, automotive, pharmaceutical, clothing, chemical and Internet commerce branches.

To sum up the discussions concerning the logistic service branch we should say that it is a classic example of an economic mesosystem. This branch is a link and a platform determining the efficient functioning of entities in the macro and microeconomic system. Business entities for which the guaranteed delivery time (e.g. 24 hours from placing an order) is the basis for their order policy, determine their functioning from the logistic service provider. It is estimated that more than $95 \%$ of small and medium enterprises as well as $90 \%$ of large enterprises in Poland use services from the logistic branch, especially express services and this tendency is growing (Fechner, Szyszka, 2012: 151).

\section{CONCLUSION}

The conducted analysis demonstrates clear and strong dependences taking place in the entire economic system of a given country and the logistic services branch. The higher the level of competitiveness and innovation of used logistic solutions, the quicker the development of other sectors of the economy. This means that the thesis formulated in the introduction has been confirmed, which means that the logistic services branch is a typical mesoeconomic system. In addition, it needs to face diverse and internationalized conditions for its development as a branch determining internal and commercial exchange between entities from around the world. Globalization processes, the integration of economies on various levels as well as variable trends in management strategies are a huge influence. All this results in the fact that this mesoeconomic system is characterized by a very high dynamics of changes in its structure as well as in the expectations of its participants.

\section{REFERENCES}

Bain, J. S. (1959), Industrial Organization, New York.

Bujak, A. (2010), Zwinne łańcuchy dostaw, Logistyka, No. 5, pp. 129

Ciesielski, M. (ed.), (2005), Rynek ustug logistycznych, Difin, Warsaw.

Fechner, I., Szyszka, G. (ed.), (2012), Logistyka w Polsce. Raport 2011, ILiM, Poznań.

Gołembska, E. (ed.) (2001), Kompendium wiedzy o logistyce, Polskie Wydawnictwo Naukowe, Warsaw. 
Gorynia, M., Jankowska, B., Maślak, E. (2000), Branża jako przedmiot badań ekonomii, Gospodarka Narodowa, No. 3 , pp. 36

Grudzewski, W. M., Hejduk, I. K. (2001), Projektowanie systemów zarządzania, Difin, Warsaw.

Grzywacz, W. (2005), Ekonomiści i systemy ekonomiczne, Polskie Towarzystwo Ekonomiczne, Szczecin.

Janasz, W. (ed.) (1997), Podstawy ekonomiki przemystu, Polskie Wydawnictwo Naukowe, Warsaw.

Janasz, W. (ed.) (2000), Elementy strategii rozwoju przemystu, Wydawnictwo Naukowe Uniwersytetu Szczecińskiego, Szczecin.

Jeszka, A. M. (2009), Sektor ustug logistycznych w teorii i praktyce, Difin, Warsaw.

Jeszka, A. M. (2013), Sektor ustug logistycznych w teorii i praktyce, Wyd. 2, Difin, Warsaw.

Krawczyk, S. (ed.) (2011), Logistyka. Teoria i praktyka, Difin, Warsaw.

Mindur, M. (ed.) (2008), Logistyka. Infrastruktura techniczna na świecie. Zarys teorii i praktyki, Warsaw-Radom 2008.

Porter, M. E. (1992), Strategia konkurencji. Metody analizy sektorów i konkurentów, Polskie Wydawnictwo Ekonomiczne, Warsaw.

Stankiewicz, M. J. (ed.) (2006), Zarządzanie wiedzą jako kluczowy czynnik międzynarodowej konkurencyjności przedsiębiorstwa, Wydawnictwo TNOiK, Toruń.

Walczak, W. (2010), Analiza czynników wptywających na konkurencyjność przedsiębiorstw, E-mentor, No. 5 (37), pp. 6 